Article

\title{
Influence of Graphite Morphology on Phase, Microstructure, and Properties of Hot Dipping and Diffusion Aluminizing Coating on Flake/Spheroidal Graphite Cast Iron
}

\author{
Yu Zhang®, Yongzhe Fan, Xue Zhao, An Du *, Ruina Ma *, Jianjun Wu and Xiaoming Cao \\ Key Lab for New Type of Functional Materials in Hebei Province, Tianjin Key Lab Material Laminating \\ Fabrication and Interface, School of Material Science and Engineering, Hebei University of Technology, \\ Tianjin 300132, China; zhangyudhj2014@126.com (Y.Z.); fyz@hebut.edu.cn (Y.F.); zhaoxue@hebut.edu.cn (X.Z.); \\ hbgdwjj@hebut.edu.cn (J.W.); caoxiaoming@hebut.edu.cn (X.C.) \\ * Correspondence: duan@hebut.edu.cn (A.D.); maryna@126.com (R.M.); \\ Tel.: +86-15902266022 (A.D.); +86-13642074657 (R.M.)
}

Received: 13 March 2019; Accepted: 10 April 2019; Published: 17 April 2019

\begin{abstract}
The influence of graphite morphology on the phase, microstructure and properties of hot dipping and diffusion aluminizing (HDDA) coating on flake/spheroidal graphite cast iron (FC/FCD) was investigated. The microstructure and properties of the HDDA coatings on FC/FCD were determined by the graphite morphology. The outer and inner layers of the HDDA coating comprised the $\mathrm{Fe}_{2} \mathrm{Al}_{5}$ and $\mathrm{FeAl}$ phases, respectively. The outer layer of HDDA on FCD was dense and uniform; however, some pores of different sizes were found in the outer coating on FC, resulting in looser HDDA coating. Hence, the wear resistance of the HDDA coating on FC was worse than that of the coating on FCD. During oxidation, many continuous oxidation channels were formed from the coating surface to the matrix in the HDDA coating on FC, resulting in the oxidation of graphite in the HDDA coating and the matrix. However, only exposed spheroidal graphite was oxidized in the HDDA coating on FCD. Thus, the high-temperature oxidation resistance of the HDDA coating on FC was also worse than that of the coating on FCD.
\end{abstract}

Keywords: graphite morphology; hot dipping and diffusion aluminizing; phase; microstructure; properties

\section{Introduction}

The valve guide is an important part of engines and a major index for evaluating engine performance. In general, the valve guide is made of cast iron due to its better castability and machinability, and lower cost than steels with similar mechanical properties [1]. Because of the long-term operation of engines, the resistance to high-temperature oxidation and wear is required for the inner wall of the valve guide [2]. Although the wear resistance of high-phosphorus $(0.35-0.65 \mathrm{wt} . \%$ P) cast iron is better than that of ordinary cast iron [3], the high-temperature oxidation resistance of high-phosphorus cast iron cannot meet engine demands. Surface treatment technology not only modifies the surface properties of cast iron effectively, but also maintains the original excellent mechanical properties of the matrix.

At present, the main surface treatment technologies for improving resistance to high-temperature oxidation and wear are hot-dip aluminizing [4], micro-arc oxidation (MAO) [5], thermal spraying [6], pack-aluminizing [7], and hot dipping and diffusion aluminizing (HDDA) [8]. Hot-dip aluminizing can improve oxidation resistance, and MAO coating on hot-dip aluminized cast iron improves both oxidation resistance and wear resistance. However, when the oxidation temperature is higher than 
the melting point of pure aluminum in the middle coating, the ceramic coating will fall off. Thermal spraying is only suitable for parts with simple shapes, and pack-aluminizing technology is relatively complex and costly. The high-temperature oxidation resistance and wear resistance can be improved by HDDA coating, due to the metallurgical combination between it and the matrix, for which the technology is simple and low-cost.

The HDDA is a composite process which includes hot-dip aluminizing and subsequent thermal diffusion treatment [9]. The diffusion treatment can improve the oxidation resistance $[10,11]$ and wear resistance [12] of aluminized steel due to the formation of a Fe-Al intermetallic phase on the surface. The $\mathrm{Fe}-\mathrm{Al}$ intermetallic coating formed during the diffusion process will react with oxygen to form a layer of alumina ceramic in the oxidation process, which can prevent cast iron from being oxidized. Moreover, the hardness of Fe-Al intermetallic phase is higher than that of cast iron. Therefore, the HDDA can effectively increase high-temperature oxidation resistance and improve the wear resistance of cast iron.

According to the graphite morphology, gray iron can be classified as flake graphite cast iron (FC), spheroidal graphite cast iron (FCD), and compacted vermicular graphite cast iron (CV). The effect of flake/spheroidal graphite morphology on the high-temperature oxidation resistance of hot-dip aluminide cast iron has been studied extensively. For example, Lin et al. [13] found that aluminide coating on FCD was superior to FC in terms of oxidation resistance. Oxidation channels formed due to the oxidation of the flake graphite, resulting in the further oxidation of the FC matrix. However, the effect of graphite morphology on diffusion and wear resistance has not been studied. In addition, the wear resistance of cast iron decreased with the increase of the oxidation resistance by hot-dip aluminizing. Hatate et al. [14] found that the wear loss of austempered cast iron increased from spheroidal to flaky graphite under both dry and wet conditions. However, the wear resistance of cast iron remains to be further improved.

In this study, the effect of flake/spheroidal graphite on the microstructure and phase of HDDA coating, as well as its high-temperature oxidation resistance and wear resistance, was studied.

\section{Materials and Methods}

\subsection{Materials}

High-phosphorus FC and FCD (Ningbo Zhongbo metal material Co. Ltd., 4 grade, fully ferritic) were used as the matrix materials in this study. The chemical composition provided by the supplier of FC/FCD is shown in Table 1. The cast iron was cut into pieces measuring $10 \mathrm{~mm} \times 10 \mathrm{~mm} \times 4 \mathrm{~mm}$ and polished using 400 \#, 800 \#, then 1200 \# SiC paper.

Table 1. Chemical composition of FC/FCD (wt.\%).

\begin{tabular}{ccccccc}
\hline Alloy & $\mathbf{C}$ & $\mathbf{S i}$ & $\mathbf{M n}$ & $\mathbf{P}$ & $\mathbf{S}$ & $\mathbf{F e}$ \\
\hline FC & 3.00 & 0.80 & 1.20 & 0.50 & 0.02 & Balance \\
FCD & 3.00 & 1.60 & 0.70 & 0.50 & 0.02 & Balance \\
\hline
\end{tabular}

\subsection{HDDA Process}

The HDDA process included hot-dip aluminizing and diffusion. The specimens for hot-dip aluminizing were cleaned ultrasonically in $10 \mathrm{wt} . \% \mathrm{NaOH}$ (AR, Tianjin Damao Chemical Reagent Factory, Tianjin, China) solution, deionized water, 20 vol. $\% \mathrm{HCl}$ (AR, Tianjin Fuqi Chemical Reagent Co. Ltd., Tianjin, China) solution and deionized water at $25^{\circ} \mathrm{C}$ for $3 \mathrm{~min}$ each, then fluxed in a mixed solution of 6 wt.\% KF (AR, Tianjin Jizhun Chemical Reagent Co. Ltd., Tianjin, China) and 4 wt.\% NaCl (AR, Tianjin Fengchuan Reagent Technologies Co. Ltd., Tianjin, China) at $100^{\circ} \mathrm{C}$ for $5 \mathrm{~min}$. During the aluminizing process, the samples were dried and preheated at $200{ }^{\circ} \mathrm{C}$ for $2 \mathrm{~min}$, then immersed in a molten aluminum bath (purity $>99.7 \%$ ) at $730{ }^{\circ} \mathrm{C}$ for $5 \mathrm{~min}$ in a well-type electrical resistance furnace (SG2-5-10, Tianjin Zhonghuan, Tianjin, China). After hot-dip aluminizing, the samples were air-cooled to room temperature. Finally, the diffusion of specimens was conducted at $950{ }^{\circ} \mathrm{C}$ in static air for $1 \mathrm{~h}$. Then, the samples were cooled in a box-type furnace (FURNACE $1300^{\circ} \mathrm{C}$, Tianjin Zhonghuan, Tianjin, China). 


\subsection{High-Temperature Oxidation}

Isothermal oxidation was performed to study the high-temperature oxidation behavior of the HDDA coating on FC/FCD. The samples were placed in a non-reactive alumina crucible. Isothermal oxidation was conducted at $750{ }^{\circ} \mathrm{C}$ in static air for 12 to $72 \mathrm{~h}$. Then, crucibles containing the samples were cooled to room temperature in air. The masses of specimens were measured using a precision electronic balance ( $0.1 \mathrm{mg}$ accuracy) after the oxidation experiment. The weight change per unit area of three specimens was averaged for each set of experimental conditions.

\subsection{Wear Resistance}

The Vickers hardness of FC/FCD with and without HDDA was measured by a microhardness tester (HMV-2T, Ningbo Op Instruments Co. Ltd., Ningbo, China) at a load of $980 \mathrm{mN}$ for $15 \mathrm{~s}$. The wear resistance of HDDA coating on FC/FCD was evaluated on a ball-on-disc tribometer (SFT-2M, Lanzhou Zhongkekaihua, Lanzhou, China) by sliding $\mathrm{Si}_{3} \mathrm{~N}_{4}$ balls ( $2 \mathrm{~mm}$ diameter) against the specimens with a load of $8 \mathrm{~N}$, sliding speed of $400 \mathrm{r} / \mathrm{min}$, sliding track diameter of $4 \mathrm{~mm}$, and duration of $20 \mathrm{~min}$ in air [15]. The 3D morphology of the wear track profile was observed using a metallographic microscope (DSX510, Hongkong OLYMPUS, Hongkong, China).

\subsection{Microstructure and Phase Analyses}

The cross-sectional and surface microstructure of the HDDA coating was examined by a Hitachi S-4800 field-emission scanning electron microscope (SEM, Suzhou Seins Instrument Co. Ltd., Suzhou, China) with energy-dispersive spectrometry (EDS). The cross-section was polished using 400 \#, 800 \#, 1200 \#, 1500 \# and 2000 \# SiC paper, then polished with a polishing cloth, and corroded 1-2 s. The phase composition of the HDDA coating was analyzed by a Rigaku DMAX-RC X-ray diffraction (XRD, Brook AXS Co. Ltd., Germany) system with $\mathrm{Cu} \mathrm{K} \alpha$ radiation. The phase composition of the inner layer was analyzed by grinding the outer layer with SiC paper and performing XRD afterward.

\section{Results and Discussion}

\subsection{Microstructure and Phase of the Hot-Dip Aluminide Coating}

Figure 1 shows the microstructure of hot-dip aluminide coating on FC/FCD hot-dip aluminized at $730{ }^{\circ} \mathrm{C}$ for $5 \mathrm{~min}$. According to the EDS (EDS analysis of needles at 3 and 6 locations is performed at 10,000 times) in Table 2 (EDS spectra in Figure 2) and the XRD results in Figure 3, the aluminide coatings on FC and FCD consist of an outer $\mathrm{Al}$ topcoat and inner $\mathrm{Fe}_{2} \mathrm{Al}_{5}$ coating, and $\mathrm{FeAl}_{3}$ is distributed in the outer Al topcoat in bulk and rod forms. These are consistent with the results reported by Lin et al. [13] and Zhang et al. [16]. From Figure 1, we can observe that the inner $\mathrm{Fe}_{2} \mathrm{Al}_{5}$ intermetallic coating of aluminized FCD grows inward as a tongue-like structure perpendicular to the matrix. However, the interface between the $\mathrm{Fe}_{2} \mathrm{Al}_{5}$ coating and $\mathrm{FC}$ matrix is fairly smooth and the $\mathrm{Fe}_{2} \mathrm{Al}_{5}$ intermetallic coating on aluminized FC $(110 \mu \mathrm{m})$ is thicker than that on the aluminized FCD $(70 \mu \mathrm{m})$. Because Si inhibits the diffusion of $\mathrm{Al}$ atoms, these differences are due to the higher Si content in FCD than that in FC $[17,18]$. It is clear that flaky/spheroidal graphite can prevent the growth of the intermetallic coating, as shown in Figure 1a,b.

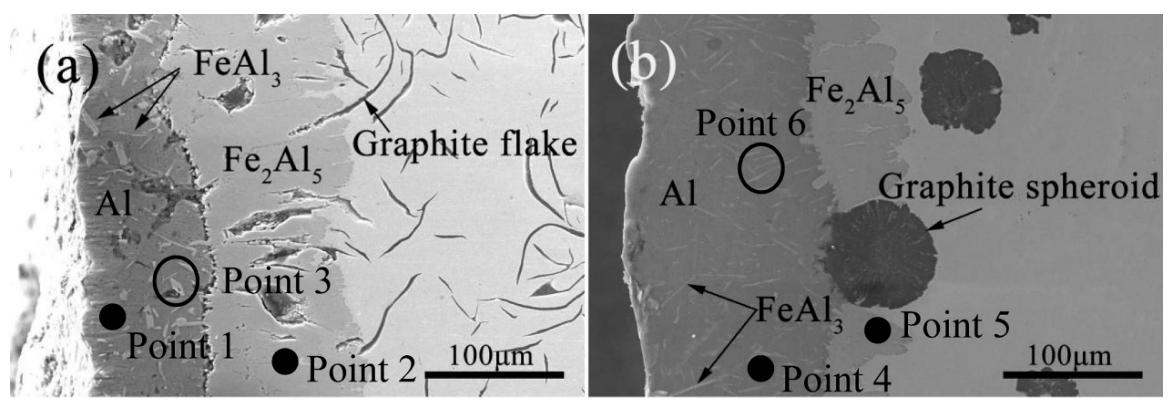

Figure 1. Cross-sectional SE microstructures of hot-dip aluminide coatings: (a) FC and (b) FCD. 

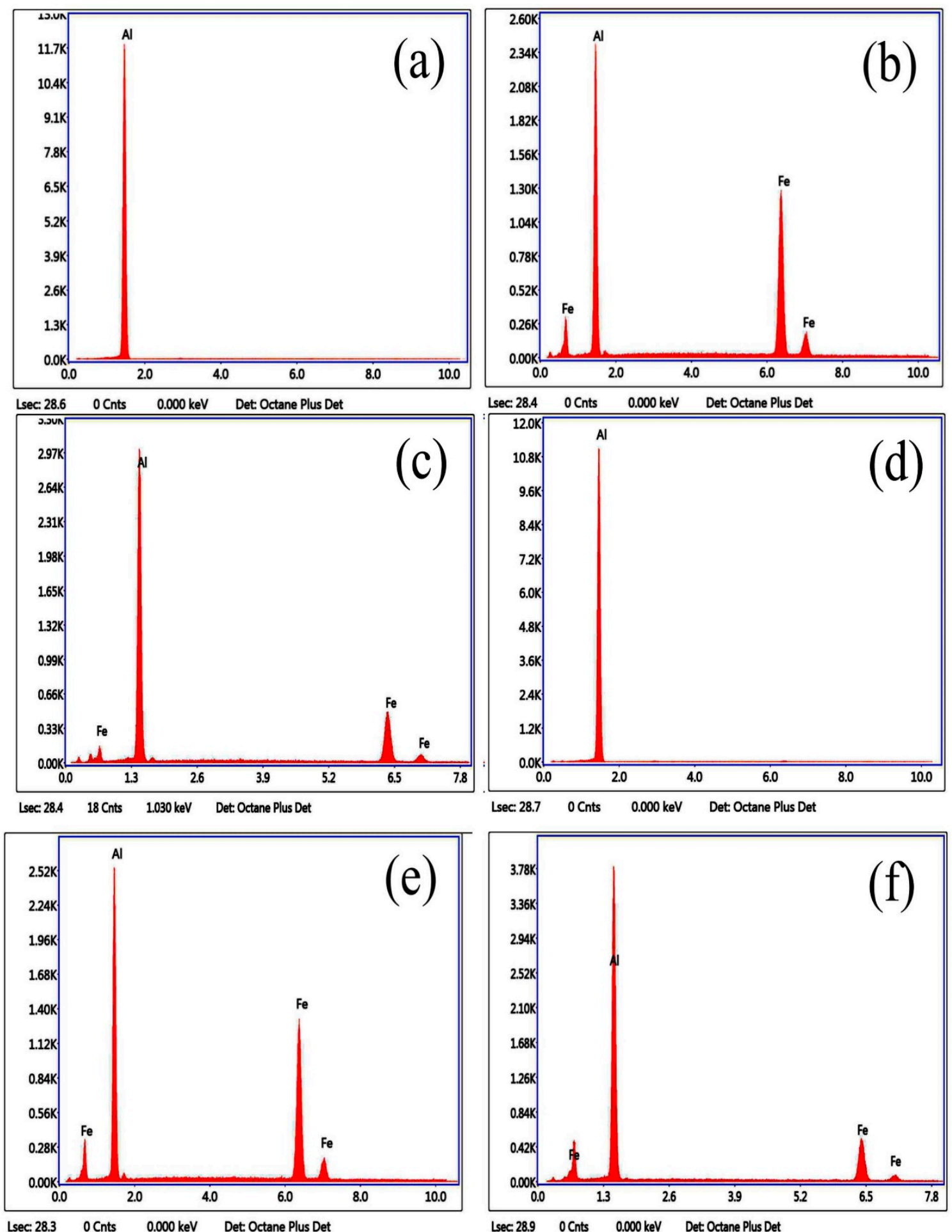

Lsec: $28.7 \quad 0$ Cnts $\quad 0.000 \mathrm{keV} \quad$ Det: Octane Plus Det

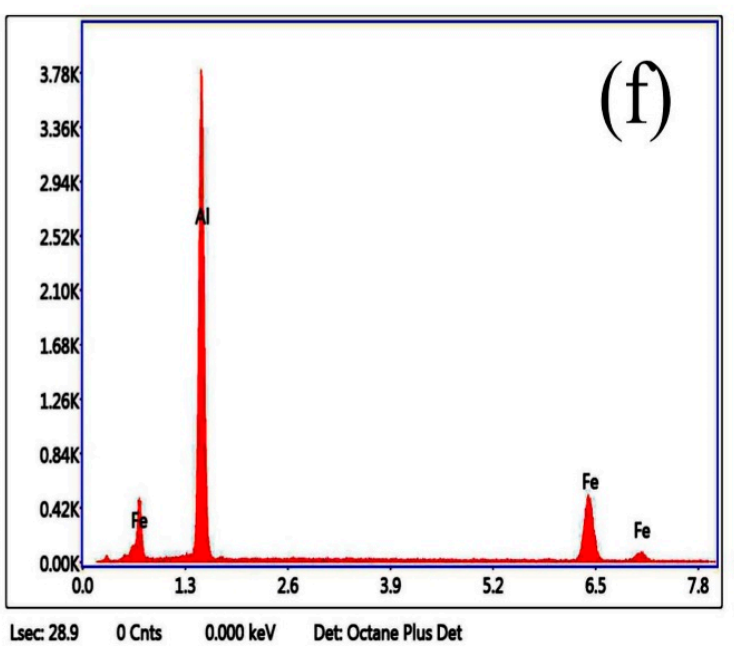

Figure 2. Spectra of different points: (a-f) Points 1-6. 

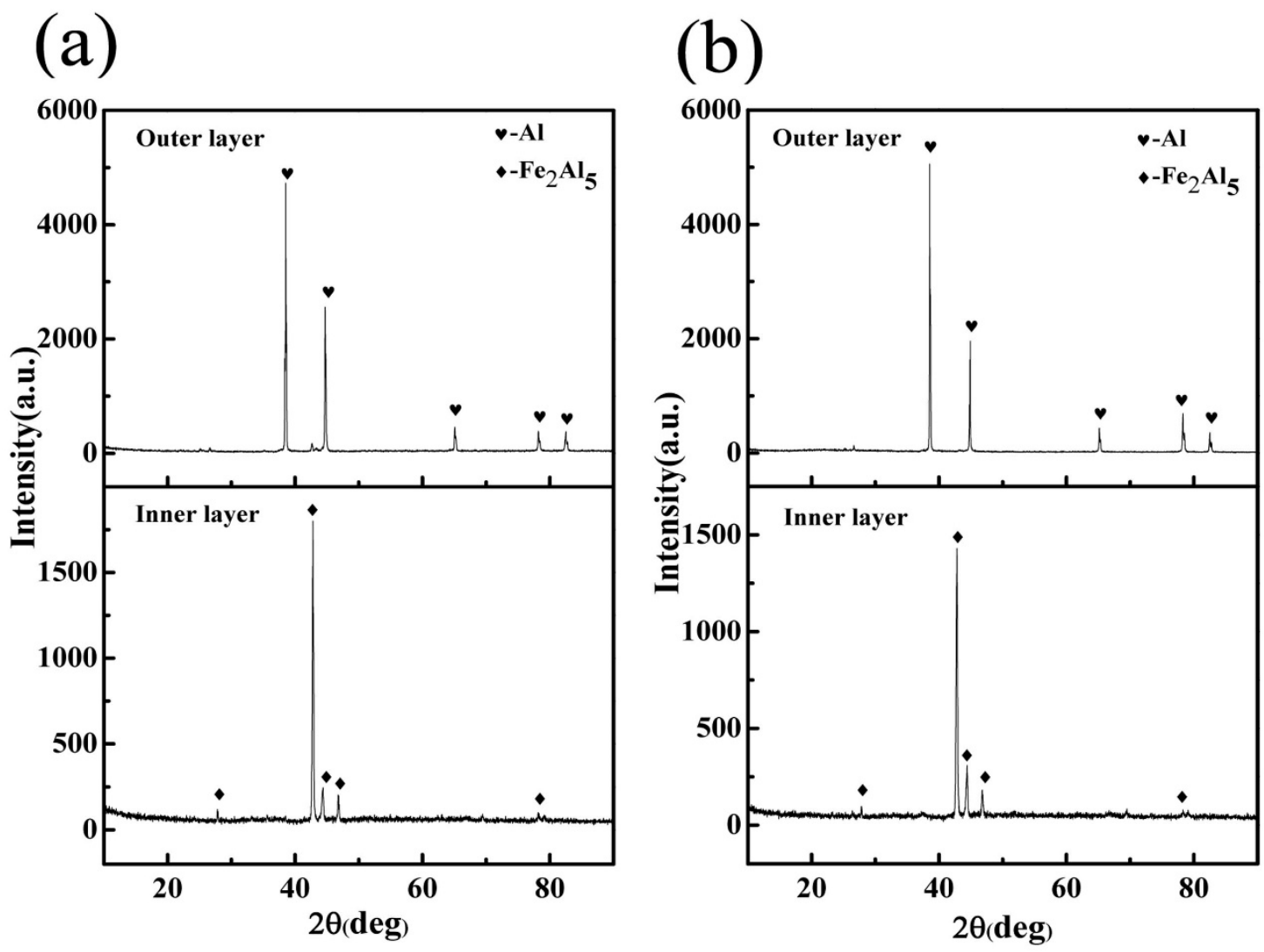

Figure 3. XRD patterns of hot-dip aluminide coatings: (a) FC and (b) FCD.

Table 2. The EDS analysis of hot-dip aluminide coatings in Figure 1.

\begin{tabular}{ccc}
\hline Point & Al (at.\%) & Fe (at.\%) \\
\hline 1 & 100.00 & 0.00 \\
2 & 70.82 & 29.18 \\
3 & 74.25 & 25.75 \\
4 & 100.00 & 0.00 \\
5 & 71.71 & 28.29 \\
6 & 76.44 & 23.56 \\
\hline
\end{tabular}

\subsection{Microstructure and Phase of the HDDA Coating}

Cross-sectional micrographs of HDDA coatings on FC and FCD diffused at $950{ }^{\circ} \mathrm{C}$ for $1 \mathrm{~h}$ after hot-dip aluminizing are shown in Figure 4a,b. Phase transformation occurs in hot-dip aluminide coating after diffusion, but the HDDA coatings on FC and FCD still consist of two layers. According to the EDS results in Table 3 (EDS spectra in Figure 5a-d) and the XRD profile in Figure $6 a$,b, the $\mathrm{Fe}_{2} \mathrm{Al}_{5} / \mathrm{FeAl}$ phase is observed on all outer/inner coatings of the two matrixes. The $\alpha-\mathrm{Al}_{2} \mathrm{O}_{3}$ coating is formed by the reaction between the $\mathrm{Al}$ atoms on the surface of the HDDA coating and oxygen in the air at high temperature. It cannot be observed in the cross-sectional micrographs due to its small thickness [19]. The interface between the outer and inner coatings, and that between the inner coating and FC, are smooth, because the Si content of FC is less than that of FCD. Furthermore, a larger amount of flaky graphite is found throughout the HDDA coating on FC. However, spheroidal graphite is embedded in the HDDA coating, as shown in Figure 4b. Apparently, the outer coating of HDDA on FCD is dense and uniform. Nevertheless, some pores of different sizes are observed in the outer coating of HDDA on FC. The graphite morphology in FC and FCD is similar to agaric-like flake and spheroidal morphology, respectively. Spherical graphite crystals are independent of one 
another, but flaky graphite crystals interact with one another. The exposed flaky graphite will be oxidized during diffusion, resulting in the oxidation of adjoining graphite crystals. Thus, some pores formed by oxidation of the tip of flake graphite are found around the flaky graphite throughout the HDDA coating. Some needles are observed in the inner coatings of the HDDA on FC and FCD, of which the growth direction is parallel to the interface between the outer and inner coatings, as shown in Figure 4c,d. According to the EDS results in Table 3 (EDS spectra in Figure 5e,f), the phase of the needles in the inner coatings of the HDDA on FC/FCD is $\mathrm{FeAl}_{2}$ phase.

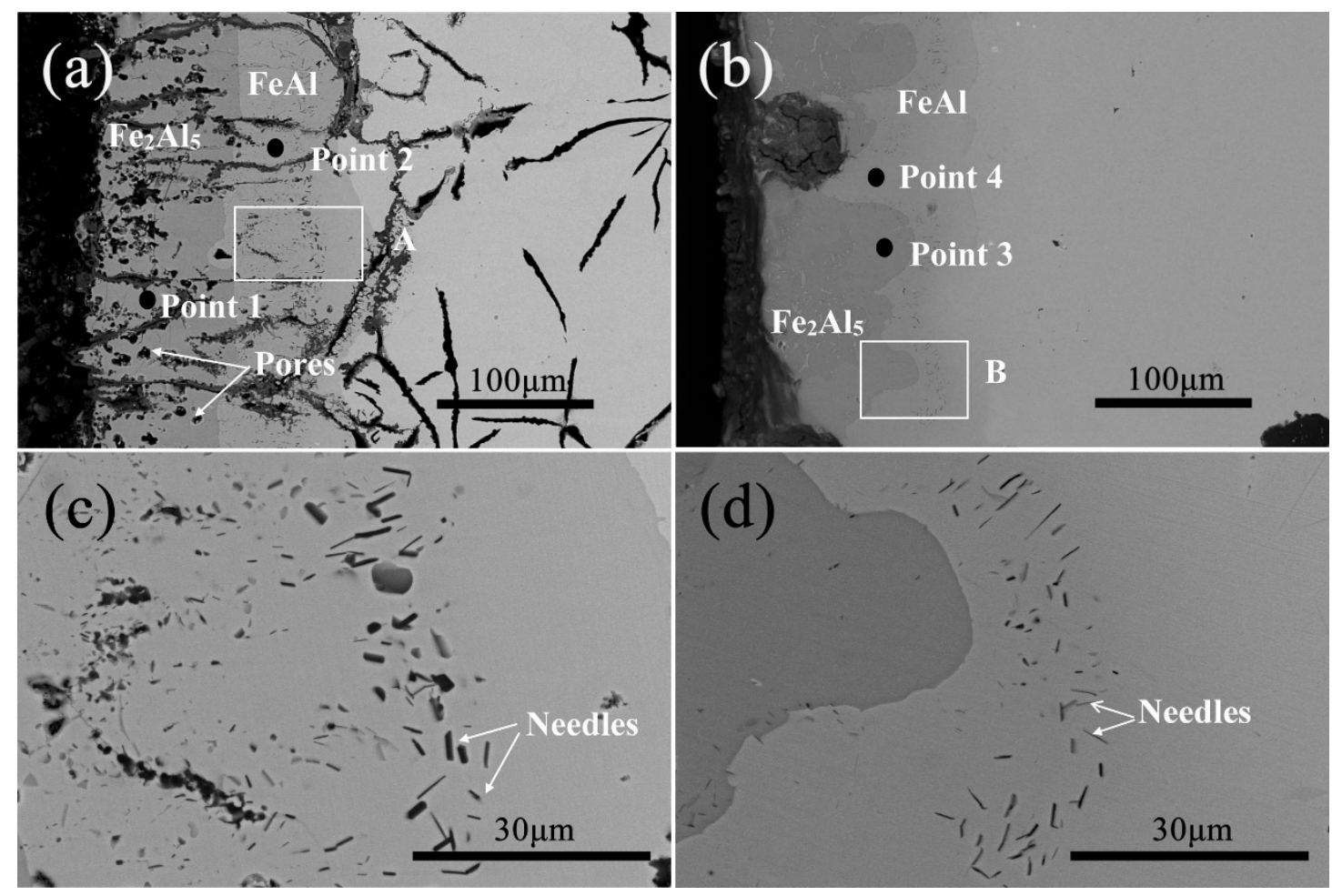

Figure 4. Cross-sectional BSE microstructures of HDDA coatings: (a) FC, (b) FCD, (c) magnified image of region $\mathrm{A}$, and (d) magnified image of region $\mathrm{B}$.

Table 3. The EDS analysis of HDDA coatings in Figure 3.

\begin{tabular}{ccc}
\hline Point & Al (at.\%) & Fe (at.\%) \\
\hline 1 & 70.91 & 29.09 \\
2 & 42.18 & 57.82 \\
3 & 70.94 & 29.06 \\
4 & 43.76 & 56.24 \\
Needle (FC) & 62.92 & 37.08 \\
Needle (FCD) & 68.69 & 31.31 \\
\hline
\end{tabular}



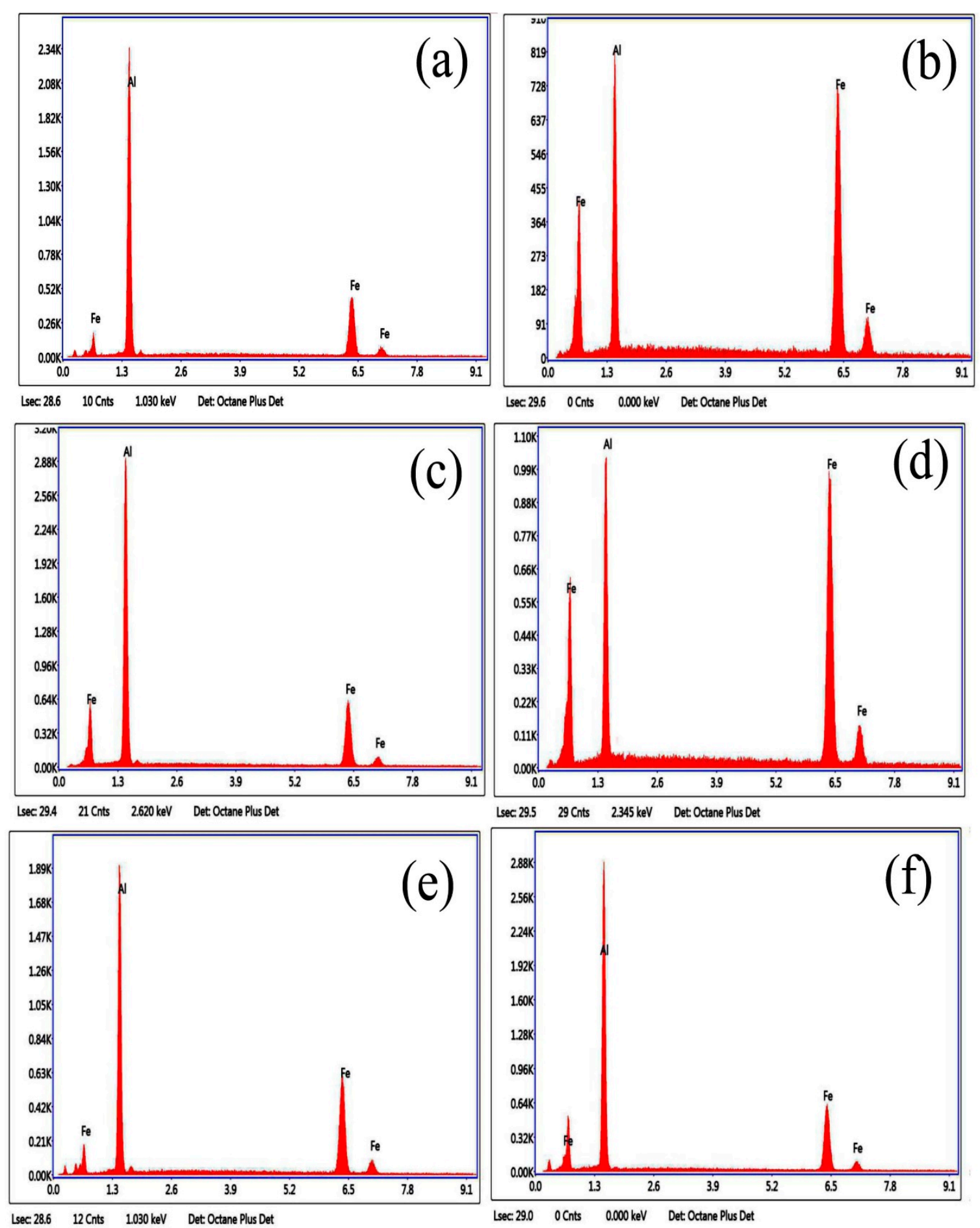

Figure 5. EDS spectra of different points: (a-d) Points 1-4, (e) Needle (FC), and (f) Needle (FCD). 
(a)

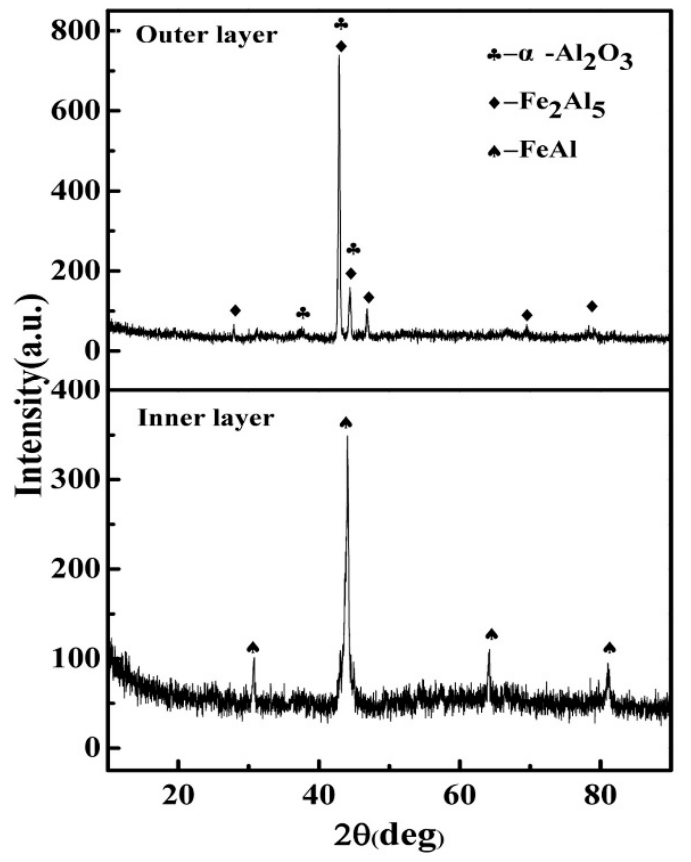

(b)

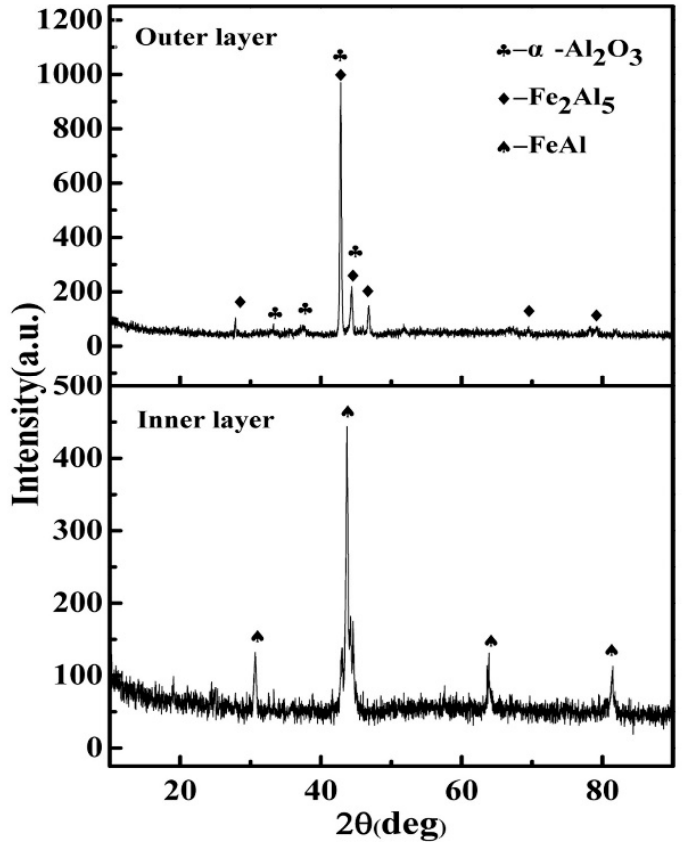

Figure 6. XRD patterns of HDDA coatings: (a) FC and (b) FCD.

\subsection{High-Temperature Oxidation}

\subsubsection{High-Temperature Oxidation Kinetic Curves}

Figure 7a shows the oxidation kinetic curves of the FC/FCD with and without HDDA coating in air at $750{ }^{\circ} \mathrm{C}$. The weight change per unit area of FC/FCD is higher than that of HDDA FC/FCD. This result indicates that HDDA can improve the high-temperature oxidation resistance of FC and FCD. The weight change per unit area of the HDDA FCD is much lower than that of HDDA FC. After $72 \mathrm{~h}$ oxidation, the weight change per unit area of the HDDA FCD is $3.6786 \mathrm{mg} / \mathrm{cm}^{2}$, which is half of HDDA FC.

(a)

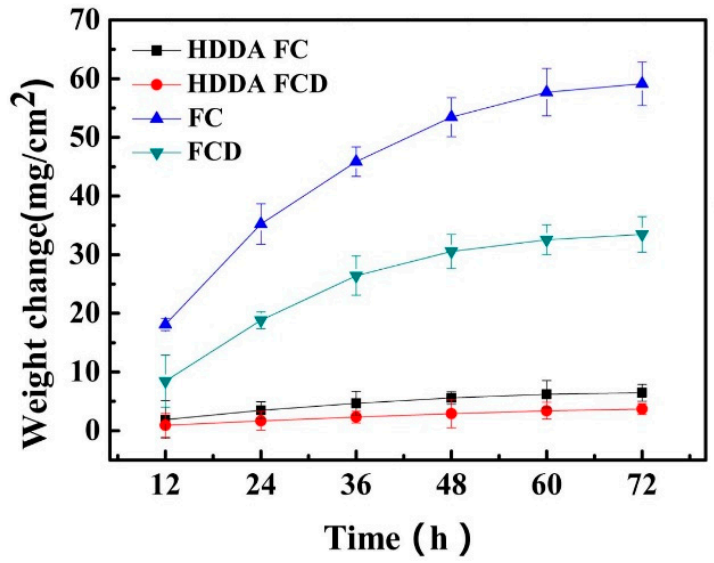

(b)

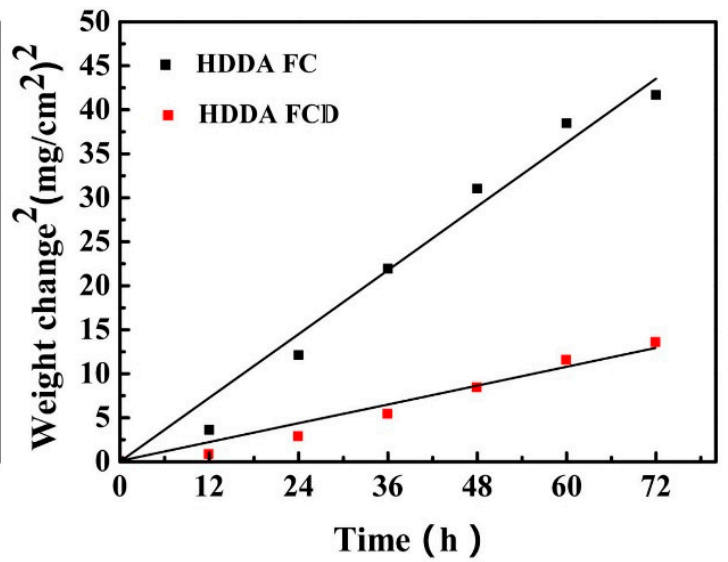

Figure 7. Oxidation kinetic curves: (a) Weight change as a function of oxidation time of FC/FCD with and without HDDA, and (b) square of weight change versus oxidation time of FC/FCD with HDDA. 
The weight change per unit area of HDDA FC/FCD follows a parabolic law in Figure 7a. Then, the oxidation kinetic curves are described by fitting the experimental data to a parabolic law (Figure $7 \mathrm{~b}$ ):

$$
\triangle m^{2}=K p \times t
$$

where $\triangle m$ is the weight change per unit area of HDDA FC/FCD, $K p$ is a constant, and $t$ is the oxidation time. The value of $K p$ can characterize the oxidation rate. The smaller the constant, the better the high-temperature oxidation resistance [20-22]. Kp can be calculated according to Equation (1); the $K p$ values for the FC and FCD are listed in Table 4. The Kp of HDDA FC is relatively high; therefore, the HDDA coating on FCD has better high-temperature oxidation resistance than that of FC. Compared to the results reported by Lin et al. [13], it can be found that the $K p$ value of HDDA is lower than that of hot-dip aluminizing. The main reason is that the oxidation resistance of Fe-Al alloy coating is better than that of Al alloy coating [9].

Table 4. The $K p\left(\mathrm{mg}^{2} / \mathrm{cm}^{4} \mathrm{~s}\right)$ of HDDA FC/FCD oxidized at $750{ }^{\circ} \mathrm{C}$.

\begin{tabular}{cc}
\hline Alloy & $\boldsymbol{K p}$ \\
\hline HDDA FC & $1.84 \times 10^{-4}$ \\
HDDA FCD & $6.13 \times 10^{-5}$ \\
\hline
\end{tabular}

\subsubsection{Microstructure and Phase of the HDDA Coating after Oxidation}

The cross-sectional BSE microstructures of HDDA FC and FCD after oxidation are shown in Figure 8a,b. The HDDA coatings on FC/FCD are composed of two layers after oxidation. According to the EDS data in Table 5 (EDS spectra in Figure 9) and the XRD data (red and black colors were used to mark before and after oxidation, respectively) in Figure 10a,b, the outer intermetallic layer comprises the $\mathrm{Fe}_{2} \mathrm{Al}_{5}$ phase and the inner layer comprises the FeAl phase in the HDDA on FC/FCD after oxidation. However, there is no obvious change in the thickness of the $\mathrm{Fe}_{2} \mathrm{Al}_{5}$ coating or $\mathrm{FeAl}$ coating because of the low oxidation temperature and short oxidation time. After oxidation, a large amount of flaky graphite is observed in the HDDA coating on FC. The color of graphite at the interface between the HDDA coating and the FC matrix region is paler than that of the FC matrix. Figure 8c,d shows magnified images of the inner coatings on FC and FCD. Some needles can be observed in the middle of the inner coatings on the two matrixes, the distribution of which is also parallel to the interface between the outer and inner coatings. Comparison of the XRD profiles before and after oxidation shows that the number of $\mathrm{Fe}_{2} \mathrm{Al}_{5}$ phase peaks decreases, but the number of $\alpha-\mathrm{Al}_{2} \mathrm{O}_{3}$ phase peaks increases. Thus, the amount of $\mathrm{Al}_{2} \mathrm{O}_{3}$ increases after oxidation [23-25].

Table 5. The EDS analysis of HDDA coatings after oxidation in Figure 6.

\begin{tabular}{ccc}
\hline Point & Al (at. \%) & Fe (at. \%) \\
\hline 1 & 72.11 & 27.89 \\
2 & 51.00 & 49.00 \\
3 & 70.91 & 29.09 \\
4 & 55.66 & 44.34 \\
\hline
\end{tabular}




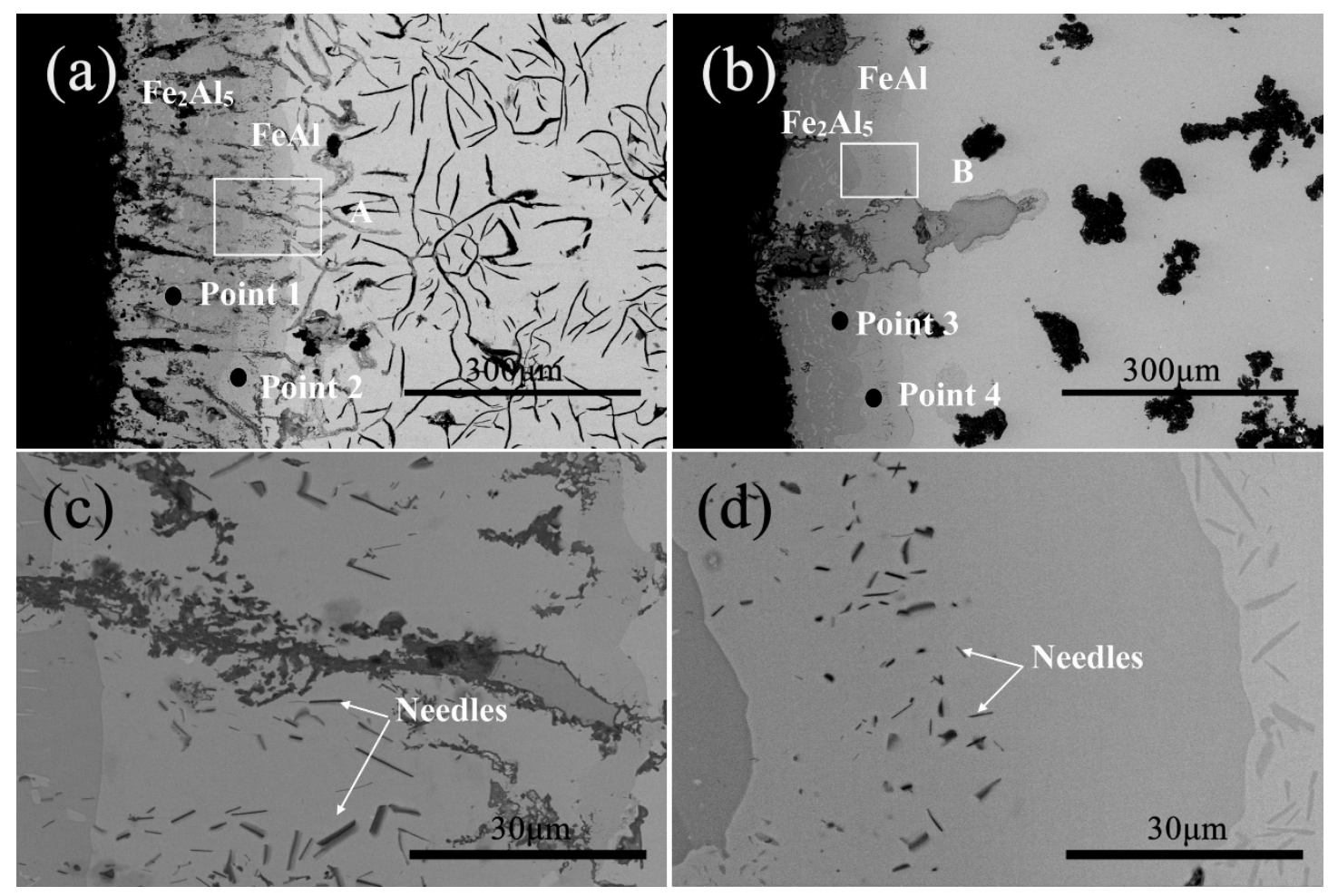

Figure 8. Cross-sectional BSE microstructures of HDDA coatings after oxidation: (a) FC, (b) FCD, (c) magnified image of regin A, and (d) magnified image of region $\mathrm{B}$.
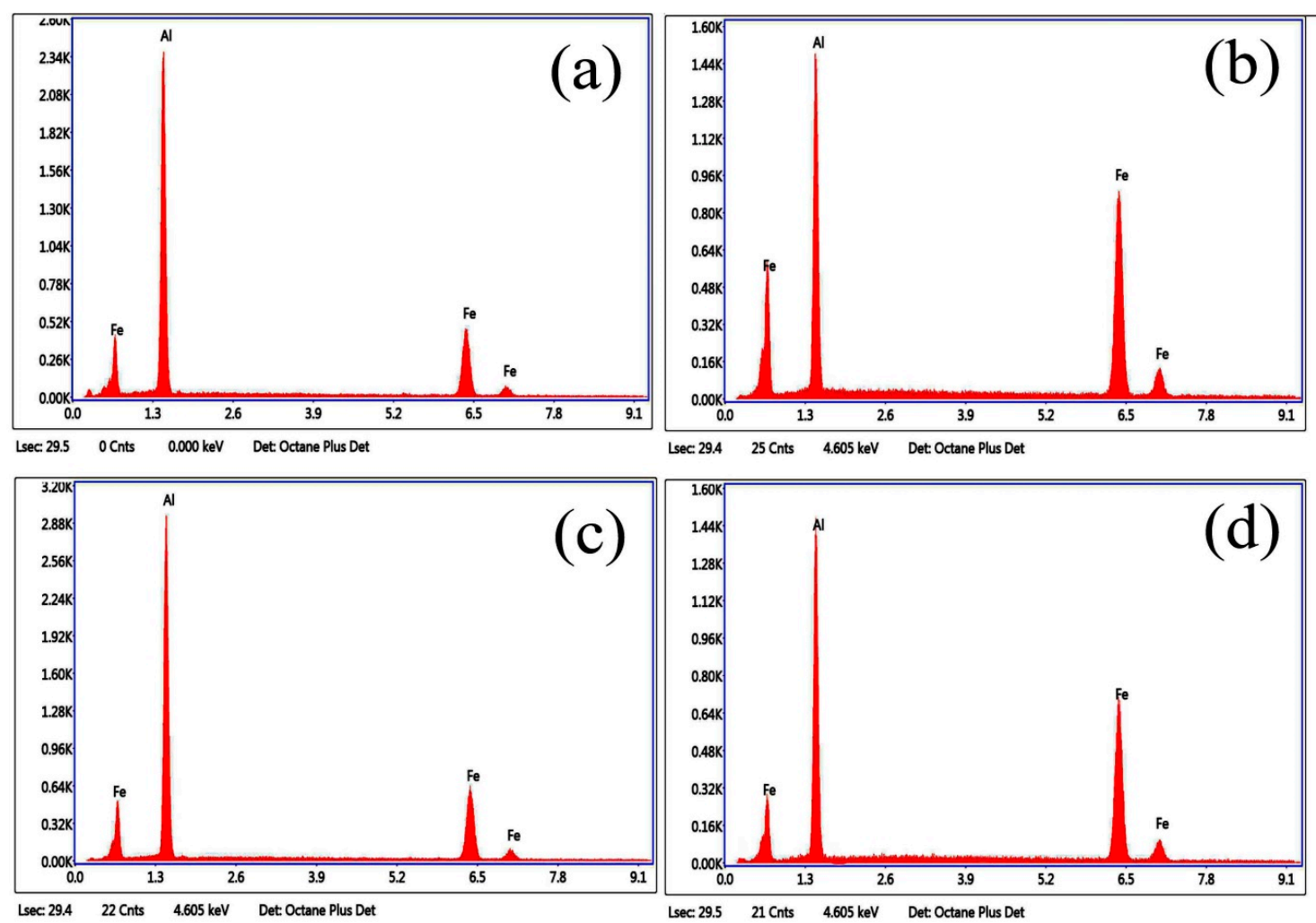

Figure 9. EDS spectra of different points: (a-d) Points 1-4. 
(a)

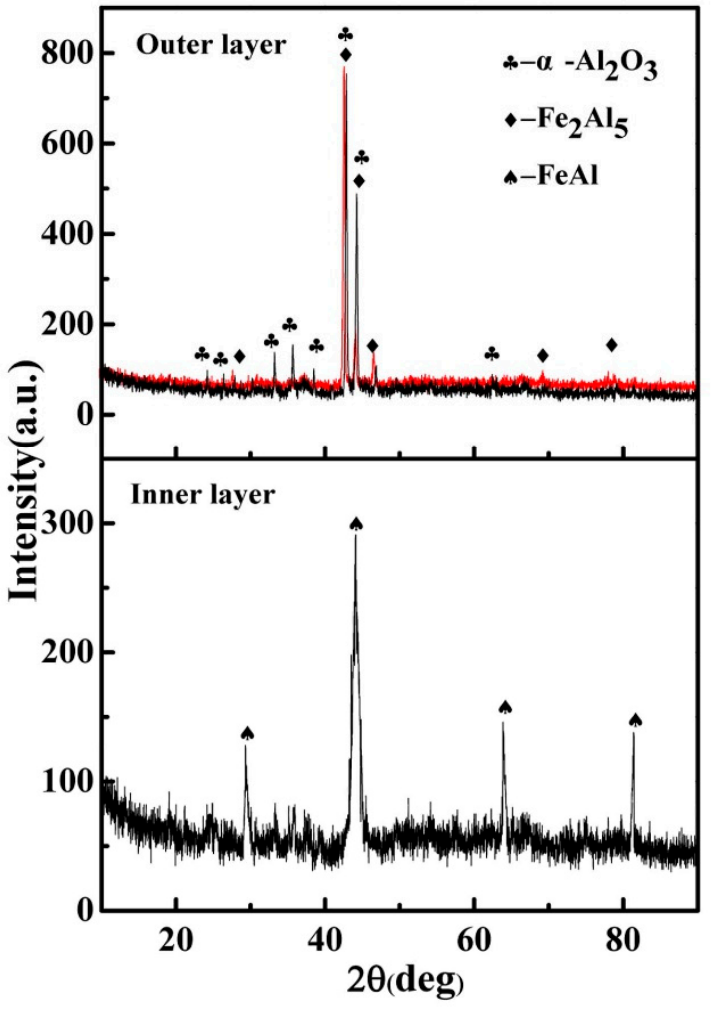

(b)

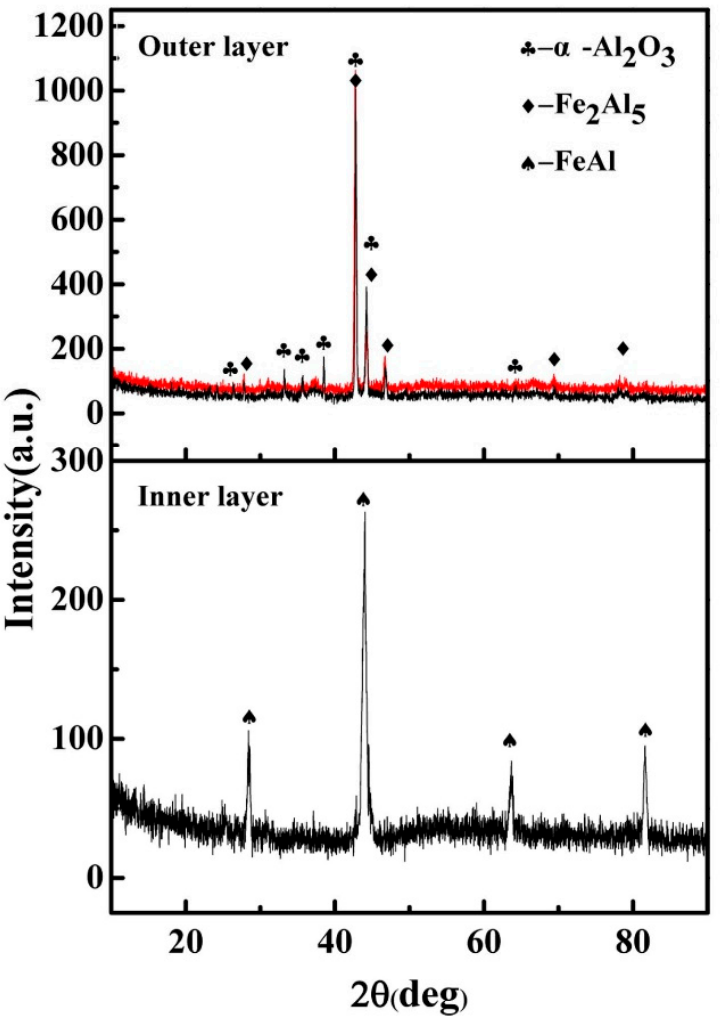

Figure 10. XRD patterns of HDDA coatings after oxidation: (a) FC and (b) FCD.

Figures 11 and 12 show the distribution of $\mathrm{Al}, \mathrm{Fe}, \mathrm{C}$, and $\mathrm{O}$ in the cross-section of the HDDA coating on FC and FCD after oxidation. Numerous $\mathrm{O}$ atoms, instead of $\mathrm{C}$ atoms, are observed in the flaky graphite throughout the HDDA coating, and many $\mathrm{O}$ atoms are distributed in the interface between the HDDA coating and matrix region (Figure 11c,d)). Therefore, the flaky graphite distributed throughout the HDDA coating is oxidized $\left(2 \mathrm{C}+\mathrm{O}_{2} \rightarrow 2 \mathrm{CO}\right.$ or $\left.\mathrm{C}+\mathrm{O}_{2} \rightarrow \mathrm{CO}_{2}\right)$. The flaky graphite at the interface between the HDDA coating and the matrix region is also oxidized to $\mathrm{CO}$ or $\mathrm{CO}_{2}$, which also explains why the color of graphite at the interface between the HDDA coating and the FC matrix region is paler than that of the $\mathrm{FC}$ matrix. However, only the exposed spheroidal graphite is oxidized ( $2 \mathrm{C}+\mathrm{O}_{2} \rightarrow 2 \mathrm{CO}$ or $\mathrm{C}+\mathrm{O}_{2} \rightarrow \mathrm{CO}_{2}$ ), while that inside the matrix and inner coating is not oxidized (Figure 12c,d). The occurrence of $\mathrm{O}$ infiltration into matrix in $\mathrm{A}$ region (Figure 12d) is quite special. Because the spheroidizing grade of FCD is 4 , a small amount of vermicular graphite is found in FCD matrix. Exposed vermicular graphite is oxidized in region $\mathrm{A}$, leading to the penetration of $\mathrm{O}$ past the HDDA coating into matrix. If the FCD is full of spherical graphite, the penetration of $\mathrm{O}$ will not occur. After oxidation of flaky graphite, many continuous oxidation channels from the surface to the matrix in the HDDA coating on FC are formed which lead to the oxidation of graphite at the interface between the HDDA coating and the matrix region and are consistent with the results reported by Lin et al. [13]. At the same time, alumina is formed around the oxidation channels in the HDDA coating, but iron oxide is formed around the oxidation channels in FC matrix. Therefore, the high-temperature oxidation resistance of the HDDA coating on FCD is much better than that on FC, which is determined by the graphite morphology. 


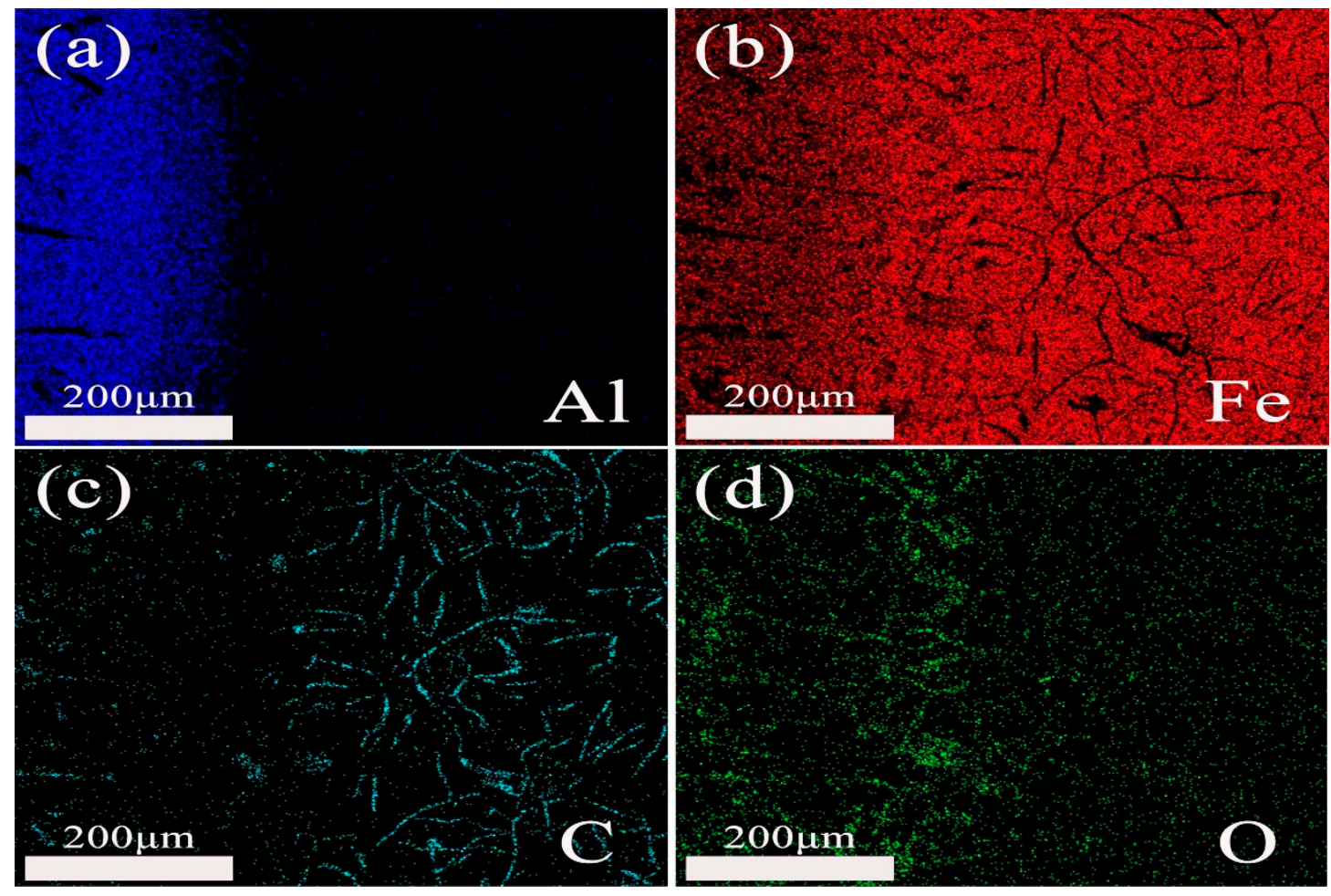

Figure 11. $\mathrm{Al}, \mathrm{Fe}, \mathrm{C}$, and $\mathrm{O}$ elemental maps of the HDDA coating on $\mathrm{FC}$ after oxidation: (a) $\mathrm{Al}$, (b) $\mathrm{Fe}$, (c) $\mathrm{C}$, and (d) O.

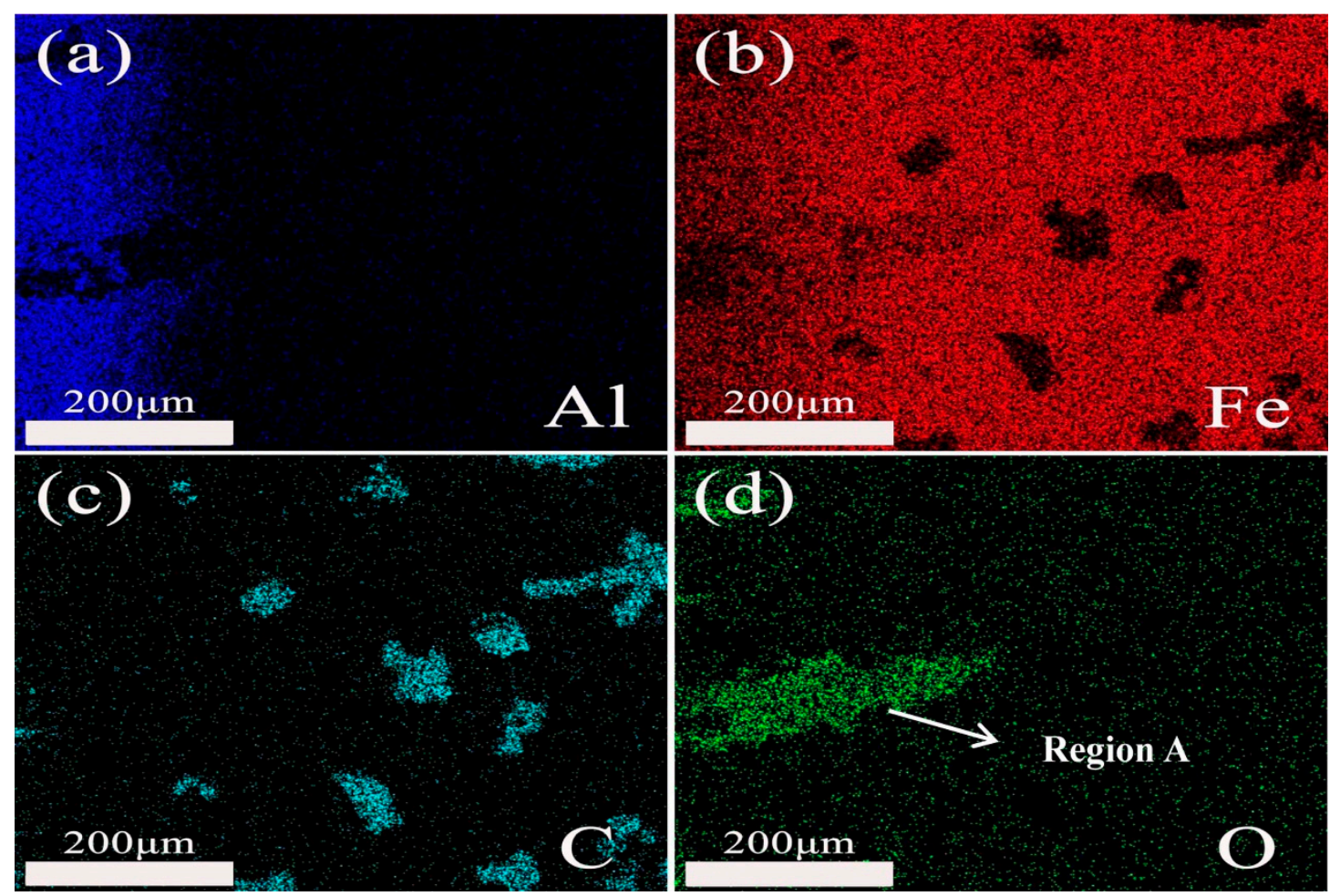

Figure 12. $\mathrm{Al}, \mathrm{Fe}, \mathrm{C}$, and $\mathrm{O}$ elemental maps of the HDDA coating on FCD after oxidation: (a) $\mathrm{Al}$, (b) Fe, (c) $\mathrm{C}$, and (d) O. 


\subsubsection{Surface Micrograph of the HDDA Coating after Oxidation}

Figure 13a,b shows the surface morphologies of the HDDA coating on FC and FCD after oxidation. The surface of the HDDA coating on FCD is dense and uniform, but the surface of HDDA FC shows peeling and warping. This is mainly due to graphite oxidation at the interface between the HDDA coating and the FC matrix region during oxidation, resulting in poor adhesion between the HDDA coating and the matrix. The XRD analysis reveals the formation of $\alpha-\mathrm{Al}_{2} \mathrm{O}_{3}$ on the surface of the HDDA coatings on FC and FCD, as shown in Figure 10a,b. As the HDDA coating falls off, the oxidation area increases. Thus, the value of the weight change of HDDA FC is larger than that of HDDA FCD.

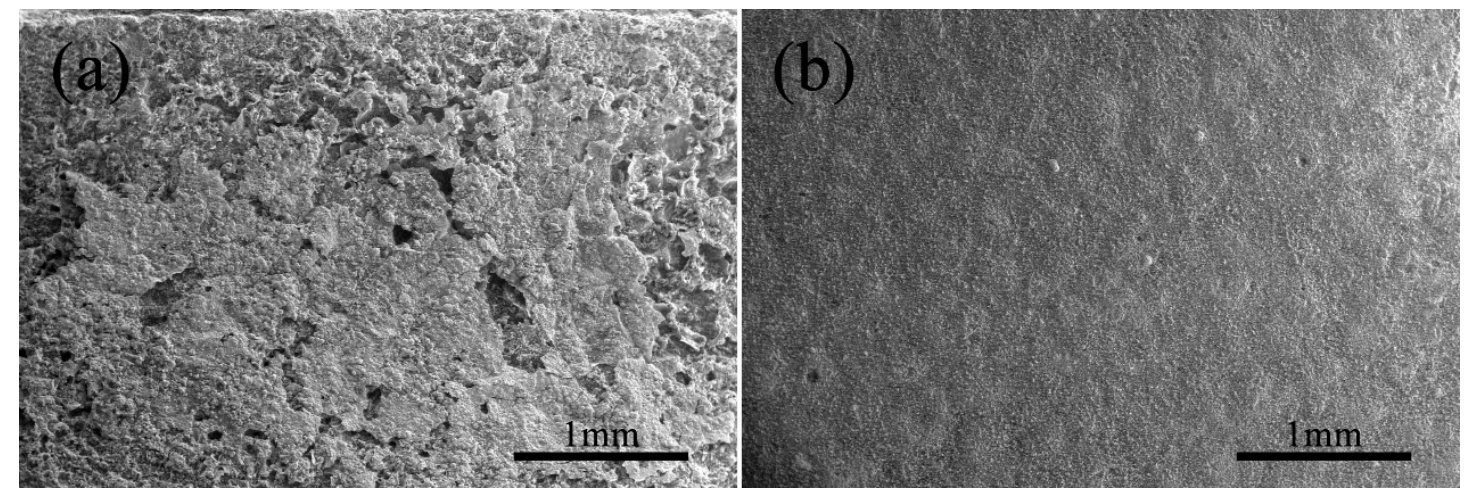

Figure 13. SE micrographs of HDDA coatings after oxidation: (a) FC and (b) FCD.

\subsection{Abrasive Wear}

\subsubsection{Hardness of the HDDA Coating}

Figure 14 shows the average Vickers hardness of FC/FCD with and without HDDA. The hardness of FC/FCD is $220 \pm 25 \mathrm{HV}$ and $250 \pm 24 \mathrm{HV}$, respectively, and the hardness of HDDA FC is $788 \pm 32 \mathrm{HV}$. However, the hardness of HDDA FCD is higher than that of HDDA FC, which is approximately $923 \pm 40 \mathrm{HV}$, as a result of the formation of pores in the outer coating of HDDA on FC.

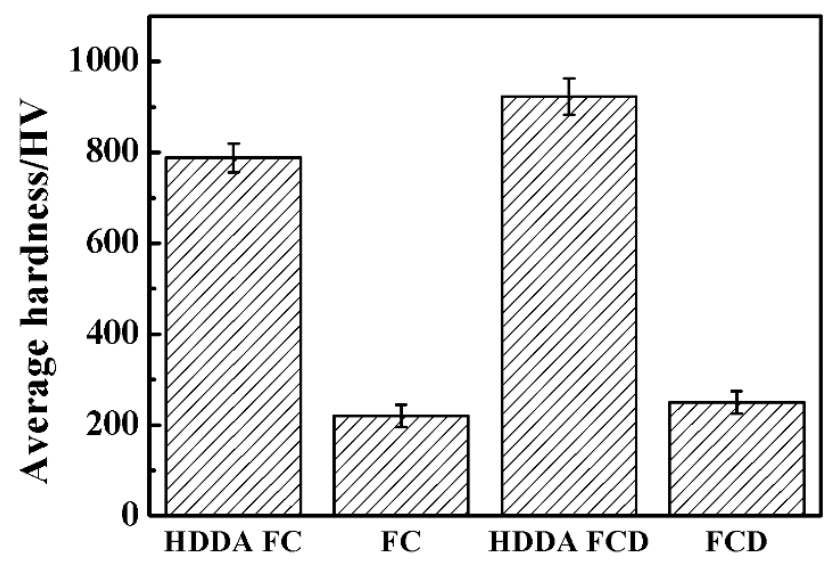

Figure 14. Average hardness of FC/FCD with and without HDDA.

\subsubsection{Friction Coefficient, Abrasion Loss and Wear Morphology}

Figure 15a displays the friction coefficients of FC/FCD and HDDA FC/FCD. The friction coefficients gradually increase and then become a relatively stable value. Evidently, the friction coefficient of the HDDA FC fluctuates between 0.26 and 0.30 , but the friction coefficient of the HDDA FC fluctuates between 0.31 and 0.32 . The fluctuation range of the friction coefficient of HDDA FC is larger than that 
of the HDDA FCD. This phenomenon can be explained by the pores formation due to flaky graphite oxidation during the diffusion process, resulting in poor internal adhesion of the $\mathrm{Fe}_{2} \mathrm{Al}_{5}$ intermetallic coating. Therefore, some particles will fall off during the wear process, resulting in greater fluctuation of the friction coefficient of HDDA FC. The average abrasion losses of FC/FCD with and without HDDA are shown in Figure 15b: $0.8108 \mathrm{~mm}^{3}, 0.5926 \mathrm{~mm}^{3}, 0.2732 \mathrm{~mm}^{3}$, and $0.3613 \mathrm{~mm}^{3}$ for HDDA FC, FC, HDDA FCD, and FCD, respectively. The lower the average abrasion loss, the better the wear resistance is [26,27]. Thus, the wear resistance of FCD can be improved by HDDA, which has no obvious effect on the wear resistance of FC. It should be noted that the friction coefficient increased after HDDA, which worth being studied further in the future.
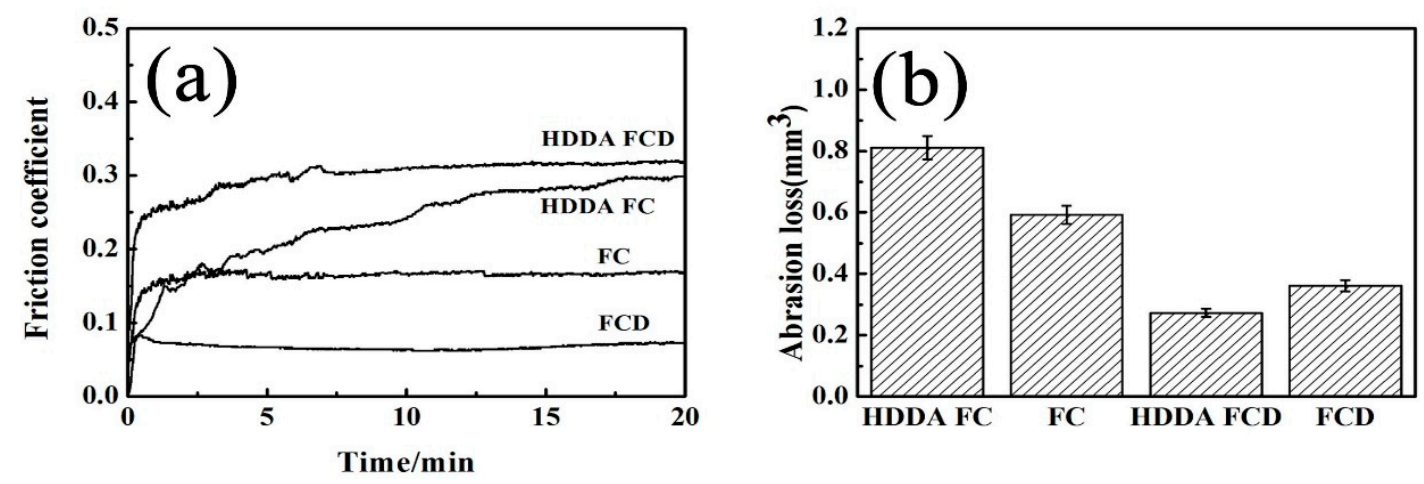

Figure 15. Friction coefficients and abrasion losses of FC/FCD with and without HDDA: (a) Friction coefficients, and (b) abrasion losses.

The 3D morphology of the wear track profile in Figure 16a,b shows the depth of the wear tracks for the HDDA coatings on FC and FCD. The depth of the grinding mark of HDDA FC is clearly greater than that of HDDA FCD in the 3D wear figure. The average wear depth and width are shown in Table 6 , and the values are consistent with the 3D profile. It can be concluded that the HDDA coating on FCD is more stable to friction and wear than that of the HDDA FC.
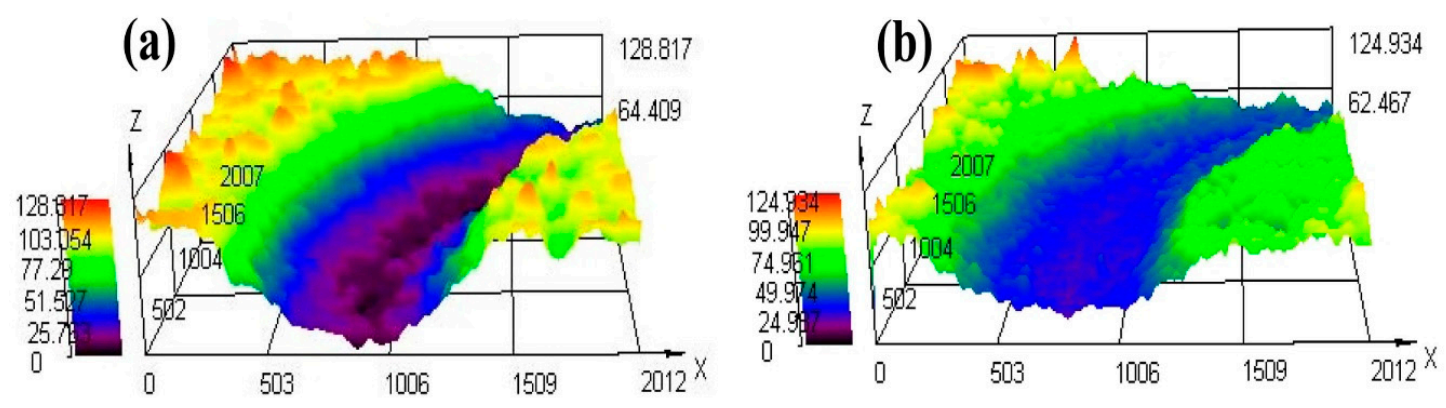

Figure 16. 3D morphologies of the wear track profiles of HDDA coatings: (a) FC and (b) FCD.

Table 6. Wear depth $(\mu)$ and wear width $(\mathrm{mm})$ of HDDA FC/FCD.

\begin{tabular}{ccc}
\hline Alloy & Wear Depth & Wear Width \\
\hline HDDA FC & 101.25 & 1.14 \\
HDDA FCD & 49.73 & 0.75 \\
\hline
\end{tabular}

\section{Conclusions}

The graphite morphology did not affect the phase composition of the HDDA coating on FC/FCD, but it determined the microstructure and properties of the coating. The HDDA coatings on FC/FCD consisted of an outer $\mathrm{Fe}_{2} \mathrm{Al}_{5}$ topcoat and an inner $\mathrm{FeAl}$ layer. A large amount of flaky graphite was 
found throughout the HDDA coating on FC, which featured some pores. However, spheroidal graphite was also embedded in the HDDA coating, resulting in a dense and uniform morphology. The flaky graphite provides a channel for the penetration of $O$ past the HDDA coating into matrix, but the spherical graphite can well prevent the penetration of $\mathrm{O}$. Therefore, the high temperature oxidation resistance and wear resistance of HDDA FCD are about three times that of HDDA FC.

Author Contributions: Writing-Original Draft Preparation, Y.Z.; Conceptualization, Y.F.; Data Curation, X.Z.; Methodology, A.D.; Resources, R.M.; Investigation, J.W.; Formal Analysis, X.C.

Acknowledgments: This work was supported by the National Natural Science Foundation of China (grant numbers 51601056, 51501055); and the Natural Science Foundation of Hebei Province of China (grant number E2017202012)

Conflicts of Interest: The authors declare no conflict of interest.

\section{References}

1. Li, K.R.; Zeng, Y.C.; Zhang, Z.C. New progress of cast iron production technology in China (2). Modern Cast Iron. 2016, 19-25. [CrossRef]

2. Zhao, W.P.; Liu, Y.J.; Wang, H.; Ding, X.H.; Yang, Y.J.; Qie, Y.L.; Liu, J.Y. Analysis and solution of fracture of valve guide for a four cylinder engine. Small Intern. Combust. Engine Veh. Tech. 2015, 44, 48-51.

3. Li, J.Y. Effect of phosphorus content on wear resistance of gray cast iron. Mech. Manag. Dev. 2005, 21-25. [CrossRef]

4. Zhang, Z.; Wang, Y.; Xiao, L.; Zhang, L.; Su, Y.; Lin, J. High-temperature oxidation of hot-dip aluminizing coatings on a $\mathrm{Ti}_{3} \mathrm{Al}-\mathrm{Nb}$ alloy and the effects of element additions. Corros. Sci. 2012, 64, 137-144. [CrossRef]

5. Zhang, B.; Cai, H.; Zhang, Y.; Sun, W.-C.; Zhang, J.-M. Effect of Oxide Film Thickness on Electrical and Thermal Conductivity of Micro-arc Oxidize Aluminium Substrates. Surf. Technol. 2017, 46, 23-27.

6. Li, Y.J.; Liang, T.Q.; Ao, R.; Zhao, H.; Chen, X.; Zeng, J. Oxidation resistance of iron-based coatings by supersonic arc spraying at high temperature. Surf. Coat. Technol. 2018, 347, 99-112. [CrossRef]

7. Bozza, F.; Bolelli, G.; Giolli, C.; Giorgetti, A.; Lusvarghi, L.; Sassatelli, P.; Scrivani, A.; Candeli, A.; Thoma, M. Diffusion mechanisms and microstructure development in pack aluminizing of Ni-based alloys. Surf. Coat. Technol. 2014, 239, 147-159. [CrossRef]

8. Fan, X.M.; Li, L.; Wen, H.Y.; Liu, S.F.; Li, Z.Q. Study on hot-diffusion aluminzing of cast iron and its high temperature oxidation resistance. Mater. Prot. 2005, 38, 48-50.

9. Wu, D.; Zhang, X.; Wang, X. Comparative study on high temperature oxidation resistance of hot-dipped aluminum and hot-diffusion aluminizing steels. Autom. Instrum. 2013, 21-22. [CrossRef]

10. Chen, N.; Wang, M.; Wang, H.-P.; Wan, Z.; Carlson, B.E. Microstructural and mechanical evolution of Al/steel interface with $\mathrm{Fe}_{2} \mathrm{Al}_{5}$ growth in resistance spot welding of aluminum to steel. J. Manuf. Process. 2018, 34, 424-434. [CrossRef]

11. Cheng, W.-J.; Wang, C.-J. High-temperature oxidation behavior of hot-dipped aluminide mild steel with various silicon contents. Appl. Surf. Sci. 2013, 274, 258-265. [CrossRef]

12. Majumdar, S.; Paul, B.; Kain, V.; Dey, G.K. Formation of $\mathrm{Al}_{2} \mathrm{O}_{3} / \mathrm{Fe}-\mathrm{Al}$ coatings on $\mathrm{SS} 316$ surface by pack aluminizing and heat treatment. Mater. Chem. Phys. 2017, 190, 31-37. [CrossRef]

13. Lin, M.B.; Wang, C.J.; Volinsky, A.A. Isothermal and thermal cycling oxidation of hot-dip aluminide coating on flake/spheroidal graphite cast iron. Surf. Coat. Technol. 2011, 206, 1595-1599. [CrossRef]

14. Hatate, M.; Shiota, T.; Takahashi, N.; Shimizu, K. Influences of graphite shapes on wear characteristics of austempered cast iron. Wear 2001, 251, 885-889. [CrossRef]

15. Wang, W.; Du, A.; Fan, Y.; Zhao, X.; Wang, X.; Ma, R.; Li, Q. Microstructure and tribological properties of SiC matrix composites infiltrated with an aluminium alloy. Tribol. Int. 2018, 120, 369-375. [CrossRef]

16. Zhang, J.W.; Fan, Y.Z.; Zhao, X.; Ma, R.; Du, A.; Cao, X. Influence of duty cycle on the growth behavior and wear resistance of microarc oxidation coatings on hot dip aluminized cast iron. Surf. Coat. Technol. 2018, 337, 141-149. [CrossRef]

17. Awan, G.H.; Hasan, F.U. The morphology of coating/substrate interface in hot-dip-aluminized steels. Mater. Sci. Eng. A 2008, 472, 157-165. [CrossRef] 
18. Lin, M.B.; Wang, C.J. Microstructure and high temperature oxidation behavior of hot-dip aluminized coating on high silicon cast iron. Surf. Coat. Technol. 2010, 205, 1220-1224. [CrossRef]

19. Nouri, S.; Rastegari, S.; Mirdamadi, S.; Hadavi, M. Formation of Diffusion Aluminide Coatings on $\gamma$-TiAl Alloy with In-Pack and Out-Pack Processes. Trans. Indian Inst. Met. 2015, 68, 867-871. [CrossRef]

20. Jeng, S.C. Oxidation behavior and microstructural evolution of hot-dipped aluminum coating on Ti-6Al-4V alloy at $800^{\circ} \mathrm{C}$. Surf. Coat. Technol. 2013, 235, 867-874. [CrossRef]

21. Lee, J.W.; Kuo, Y.C. A study on the microstructure and cyclic oxidation behavior of the pack aluminized Hastelloy X at $1100^{\circ}$ C. Surf. Coat. Technol. 2006, 201, 3867-3871. [CrossRef]

22. Wang, C.J.; Badaruddin, M. The dependence of high temperature resistance of aluminized steel exposed to water-vapour oxidation. Surf. Coat. Technol. 2011, 205, 1200-1205. [CrossRef]

23. Wang, H.-X.; Zhang, Y.; Cheng, J.-L.; Li, Y.-S. High temperature oxidation resistance and microstructure change of aluminized coating on copper substrate. Trans. Nonferrous Met. Soc. China 2015, 25, 184-190. [CrossRef]

24. Khoshhal, R. Investigation of oxidation behavior of synthesized $\mathrm{Fe}_{2} \mathrm{Al}_{5}$ and FeAl. Metal Powder Report. 2019, 74, 30-34. [CrossRef]

25. Wang, Y.S.; Xiong, J.; Yan, J.; Fan, H.; Wang, J. Oxidation resistance and corrosion behavior of hot-dip aluminized coatings on commercial-purity titanium. Surf. Coat. Technol. 2011, 206, 1277-1282. [CrossRef]

26. Zhang, X.-M.; Chen, W.-P. Review on corrosion-wear resistance performance of materials in molten aluminum and its alloys. Trans. Nonferrous Met. Soc. China 2015, 25, 1715-1731. [CrossRef]

27. Zhang, Q.; Zhou, Y.; Liu, J.; Chen, K.; Mo, J.; Cui, X.; Wang, S. Comparative research on dry sliding wear of hot-dip aluminized and uncoated AISI H13 steel. Wear 2015, 344, 22-31. [CrossRef]

(C) 2019 by the authors. Licensee MDPI, Basel, Switzerland. This article is an open access article distributed under the terms and conditions of the Creative Commons Attribution (CC BY) license (http://creativecommons.org/licenses/by/4.0/). 